This is the author's final, peer-reviewed manuscript as accepted for publication. The publisher-formatted version may be available through the publisher's web site or your institution's library.

\title{
Registration of a hard red winter wheat genetic stock homozygous for ph1b for facilitating alien introgression for crop improvement
}

Bernd Friebe, Lili Qi, Cheng Liu, Wenxuan Liu, and Bikram S. Gill

How to cite this manuscript

If you make reference to this version of the manuscript, use the following information:

Friebe, B., Qi, L., Liu, C., Liu, W., \& Gill, B. S. (2012). Registration of a hard red winter wheat genetic stock homozygous for ph1b for facilitating alien introgression for crop improvement. Retrieved from http://krex.ksu.edu

\section{Published Version Information}

Citation: Friebe, B., Qi, L., Liu, C., Liu, W., \& Gill, B. S. (2012). Registration of a hard red winter wheat genetic stock homozygous for ph1b for facilitating alien introgression for crop improvement. Journal of Plant Registrations, 6(1), 121-123.

Copyright: @ Crop Science Society of America

Digital Object Identifier (DOI): doi:10.3198/jpr2011.05.0273crgs

Publisher's Link: https://www.crops.org/publications/jpr/abstracts/6/1/121

This item was retrieved from the K-State Research Exchange (K-REx), the institutional repository of Kansas State University. K-REx is available at http://krex.ksu.edu 


\section{但 CROP SCIENCE}

\section{Registration of a hard red winter wheat genetic stock homozygous for $p h 1 b$ for facilitating alien introgression for crop improvement}

\begin{tabular}{|r|l|}
\hline Journal: & Crop Science \\
\hline Manuscript ID: & Draft \\
\hline Manuscript Type: & 11 . Crop Registration-Genetic Stock \\
\hline Divisions: & C1 crop breeding \& genetics \\
\hline Date Submitted by the & n/a \\
\hline Author: & $\begin{array}{r}\text { Friebe, Bernd; Kansas State University, Department Plant } \\
\text { Pathology, Wheat Genetic and Genomic Resources Center } \\
\text { Qi, Lili; USDA-ARS, Norther Crop Science Laboratory } \\
\text { Liu, Cheng; University of Electronic Science and Technology, School } \\
\text { of Life Science and Technology } \\
\text { Liu, Wenxuan; Henan Agricultural University, Laboratory of Cell and } \\
\text { Chromosome Engineering, College of Life Sciences } \\
\text { Gill, Bikram; Kansas State University, Department Plant Pathology, } \\
\text { Wheat Genetic and Genomic Resources Center }\end{array}$ \\
\hline Keywords: & \begin{tabular}{l} 
Crop cytology, Crop genetics, Wheat \\
\hline
\end{tabular} \\
\hline
\end{tabular}

\section{SCHOLARONE \\ Manuscripts}


Registration of a hard red winter wheat genetic stock homozygous for phlb for facilitating alien introgression for crop improvement

\section{Bernd Friebe, Lili Qi, Cheng Liu, Wenxuan Liu, and Bikram S. Gill}

Bernd Friebe, Bikram S. Gill, Wheat Genetic and Genomic Resources Center and Department of Plant Pathology, Throckmorton Plant Sciences Center, Kansas State University, Manhattan, KS 66506-5502, USA;

Lili Qi, USDA-ARS, Northern Crop Science Laboratory, 1605 Albrecht Blvd N, Fargo, ND 58102-2765, USA;

Cheng Liu, School of Life Science and Technology, University of Electronic Science and Technology of China, Chengdu, Sichuan 610054, PR China;

Wenxuan Liu, Laboratory of Cell and Chromosome Engineering, College of Life Sciences, Henan Agricultural University, Zhengzhou, Henan 450002, PR China. 


\begin{abstract}
Wild relatives of bread wheat, Triticum aestivum L. are an important source for disease and pest resistance that can be exploited in wheat improvement. However, in wheat/alien species hybrids the pairing homoeologous gene, $P h l$, suppresses the pairing and recombination of wheat and alien chromosomes and, thus, no alien genetic transfer can occur. However, in plants nullisomic for the $P h l$ gene, and in the phlb mutant stock, having a large deletion at the Phl locus, homoeologous wheat and alien chromosomes can pair and recombine. The original phlb mutant stock is in Chinese Spring background, which has poor agronomic characteristics and several backcrosses with adapted wheat cultivars are necessary before the agronomic performance of the recombinants can be evaluated. The present report describes the transfer and characterization of the phlb mutant allele into adapted Kansas winter wheat, which will accelerate the evaluation and utilization of wheat alien recombinants in cultivar improvement.
\end{abstract}

Interspecific hybridization and chromosome engineering have played an important role in wheat crop improvement (Friebe et al. 1996). The diploid-like chromosome pairing behavior of hexaploid wheat, Triticum aestivum $\mathrm{L}$. $(2 \mathrm{n}=6 \mathrm{x}=42$, AABBDD) (Riley and Chapman, 1958; Sears and Okamoto, 1958) and the tetraploid wheat species T. turgidum $(2 \mathrm{n}=4 \mathrm{x}=28, \mathrm{AABB})$ and T. timopheevii $(2 \mathrm{n}=4 \mathrm{x}=28, \mathrm{AAGG})$ (Dhaliwal 1977; Giorgi 1978) is controlled by $P h 1$, a pairing homoeologous gene. In wheat/alien species hybrids containing genomes other than A, B, D or G, Phl gene suppresses pairing of alien 
chromosomes with wheat chromosomes. As a practical consequence, no alien genetic transfers can occur in the presence of $P h l$ gene. However, in plants nullisomic for $P h 1$ gene (Riley and Chapman 1958) or in hybrids containing genes that are epistatic to Phl gene (Dover and Riley, 1972; Dvorak et al. 2006), homoeologous chromosomes can pair and recombine. Sears (1977) used radiation treatment to produce a phlb mutant stock in Chinese Spring (CS) wheat. The CSphlb mutant stock has a large deletion at the Phl locus spanning about 70 Mbp (Gill and Gill, 1991; Dunfort et al., 1995). In homozygous phlb plants, meiotic metaphase I pairing is no longer restricted to homologous chromosomes but also can occur among homoeologous wheat chromosomes and between homoeologous wheat and alien chromosomes. The CSphlb mutant stock, has been widely used in inducing homoeologous recombination between wheat and homoeologous alien chromosomes and in wheat crop improvement (Friebe et al. 1996; Qi et al. 2007).

The original phlb mutant stock (TA3809) was isolated in Chinese Spring background, an old land race from China that has poor agronomic characteristics. The Chinese Spring stocks must be used for producing desirable wheat-alien chromosome recombinants and several backcrosses with adapted wheat cultivars are necessary before the agronomic performance of the recombinants can be evaluated. Thus, it would be desirable to have the phlb mutant allele in an advanced wheat background and the present report describes the transfer of phlb into an adapted Kansas wheat cultivar.

\section{Methods}


Previously, several markers were reported that tag the phlb deletion (Roberts et al. 1999; Segal et al. 1997). Two PCR-based markers WGP90 and PSR2120 were used to detect the homozygous phlb mutant in the first two generations of $\mathrm{F}_{2}$ and $\mathrm{BC}_{1} \mathrm{~F}_{2}$. In $\mathrm{BC}_{2} \mathrm{~F}_{2}$, we used a pair of barley chromosome 5H-specific STS-PCR primers ABC302.3, (forward primer: 5'-ATAAAGGAGAAGATTGAGTC-3'; reverse primer: 5'ATAAGGAACAGGAACAGAGT-3') to identify plants that were homozygous for $p h 1 b$ (Blake et al., 1996; Wang et al., 2002). The primers amplify two fragments in Chinese Spring (CS). The top fragment is 5B-specific and bottom one is 5A-specific (Wang et al., 2002). The top fragment of about $920 \mathrm{bp}$ (designated as $\left.\mathrm{ABC}_{920}\right)$ is the $P h 1$-specific band that is absent in the CSphlb mutant stock TA3809 and 5BL deletion stocks, but 5Aspecific fragment is present in both lines (Fig. 1). The 5A-fragment serves as an internal control to rule out the possibility of PCR errors leading to the missing 5B-fragment in phlb mutant.

STS-PCR reactions were performed in $15 \mu \mathrm{L}$ of reaction mixture containing $1 \mathrm{x}$ PCR buffer (Bioline USA Inc., Taunton, MA, USA); $2 \mathrm{mM} \mathrm{MgCl} 2,0.25 \mathrm{mM}$ dNTPs; 5 pmol forward primer and reverse primer, respectively; 0.02 unit/ $\mu 1$ of Taq DNA polymerase (Bioline USA Inc., Taunton, MA, USA); and $90 \mathrm{ng}$ of genomic DNA. Genomic DNA was isolated using a BioSprint work station following the protocol as described in the BioSprint DNA Plant Handbook (Cat. no. 941558, QIAGEN Inc., Valencia, CA, USA). PCR reaction cocktails were initially denatured at $95^{\circ} \mathrm{C}$ for $5 \mathrm{~min}$, and then amplified 35 cycles of $1 \mathrm{~min}$ at $95^{\circ} \mathrm{C}, 1 \mathrm{~min}$ at $48^{\circ}-55^{\circ} \mathrm{C}$ dependant primers), and $2 \mathrm{~min}$ at $72^{\circ} \mathrm{C}$ followed by a final extension reaction of $8 \mathrm{~min}$ at $72^{\circ} \mathrm{C}$. PCR products 
were resolved on $1.5 \%$ agarose gels in $1 \mathrm{x}$ TBE and visualized by Ethidium bromide staining under UV light.

\section{Characteristics}

The phlb mutant stock TA3809 was crossed with the Kansas hard red winter wheat Overley, and the $F_{1}$ was selfed and screened by molecular markers to identify plants homozygous for phlb. These plants were again crossed with Overley, selfed, and screened to identify plants homozygous for $p h l b$. Homozygous $p h l b$ plants were crossed with Overley/Amadina (O/A) derived lines, selfed, and screened by molecular markers to identify plants homozygous for phlb. The genotype of these plants, which are about $88 \%$ in adapted winter wheat background, were verified by the primer ABC302 (Fig. 1).

Meiotic metaphase I pairing was analyzed in some of these plants to verify that they are high pairing, and the data are summarized in Table 1. The O/Aphlb plants had multivalents in about $46 \%$ of their pollen mother cells, which is slightly higher than the level in the original CSphlb stock (Table 1, Fig. 2). The O/Aphlb stock had a reduced fertility with 38 seeds per spike compared to 54 seeds per spike of Chinese Spring wheat. The O/Aph1b stock was released as KS12WGGRC55 (TA5092).

\section{Availability}


The $\mathrm{O} / \mathrm{A} p h 1 b$ mutant stock is maintained at the Wheat Genetic and Genomic Resources Center housed at the Department of Plant Pathology at Kansas State University. Seeds of KS12WGGRC55 (TA5092) are available upon request and we request that appropriate recognition to be made of the source when this genetic stock contributes to the development and release of a new germplasm, breeding line, or a cultivar.

\section{Acknowledgment}

This research was supported by grants from the Kansas Wheat Commission, the Kansas Crop Improvement Association and a special USDA-NIFA grant to Wheat Genetic and Genomic Resources Center at Kansas State University. This paper is contribution number 11-337-J from the Kansas Agricultural Experiment Station, Kansas State University, Manhattan, Kansas, 66506-5502. 


\section{References}

Dhaliwal, H.S. 1977. The $P h$ gene and the origin of tetraploid wheats. Genetics 47:177182.

Dvorak, J., K.R. Deal, and M.C. Luo. 2006. Discovery and mapping of wheat Phl suppressors. Genetics 147:17-27.

Blake, T.K., D. Kadyrzhanova, K.W. Shepherd, A.K.M.R. Islam, D.L. Langridge, C.L. McDonald, J. Erpelding, N.K. Blake, S. Larson, and L.E. Talbert. 1996. STS-PCR markers appropriate for wheat-barley introgression. Theor. Appl. Genet. 93:826832.

Dover, G.A., and R. Riley. 1972. Prevention of pairing of homoeologous meiotic chromosomes of wheat by an activity of supernumerary chromosomes of Aegilops. Nature 240:1159-161.

Dunford, R.P., N. Kurata, D.A. Laurie, T.A. Money, Y. Minobe, and G. Moore. 1995. Conservation of fine-scale DNA marker order in the genome of rice and the Triticeae. Nucleic Acids Res. 23: 2724-2728.

Friebe, B., J. Jiang, W.J. Raupp, R.A. McIntosh, and B.S. Gill. 1996. Characterization of wheat-alien translocations conferring resistance to diseases and pests: current status. Euphytica 91:59-87. 
Gill, K.S., and B.S. Gill. 1991. A DNA fragment mapped within the submicroscopic deletion of $P h 1$, a chromosome pairing regulator gene in polyploidy wheat. Genetics 129:257-259.

Giorgi, B. 1978. A homoeologous pairing mutant isolated in Triticum durum cv. Cappelli. Mut. Breed. Newsl. 11:4-5.

Qi, L.L., B. Friebe, P. Zhang, and B.S. Gill. 2007. Homoeologous recombination, chromosome engineering and crop improvement. Chromosome Res. 15:5-19.

Riley, R., and V. Chapman. 1958. Genetic control of cytogenetically diploid behavior in hexaploid wheat. Nature 182:713-715.

Roberts, M.A., S.M. Reader, C. Dalgliesh, T.E. Miller, T.N. Foote, L.J. Fish, J.W. Snape, and G.Moore. 1999. Induction and characterization of Phl wheat mutants. Genetics 153:1909-1918.

Sears, E.R. 1977. An induced mutant with homomoeologous pairing in common wheat. Can. J. Genet. Cytol. 19:585-593.

Sears, E.R., and M. Okamoto, 1958. Intergenomic chromosome relationships in hexaploid wheat. Proc. $10^{\text {th }}$ Int. Congress of Genetics, Montreal, 2:258-259.

Segal, G., B. Liu, J.M. Vega, S. Abbo, M. Rodova, and M. Feldman. 1997. Identification of a chromosome-specific probe that maps within the $P h l$ deletion in common and durum wheat. Theor. Appl. Genet. 94:968-970.

Wang, X., J. Lai, G. Liu, and F. Chen F. 2002. Development of a scar marker for the $P h 1$ locus in common wheat and its application. Crop Sci. 42:1365-1368. 
Table 1: Meiotic metaphase I pairing configurations in pollen mother cells (PMCs) homozygous phlb genotypes in Chinese Spring CS) and Overley/Amadina (O/A) backgrounds.

\begin{tabular}{|c|c|c|}
\hline Genoytpe & Number of normal PMCs & $\begin{array}{c}\text { Number of PMCs with } \\
\text { multivalents }\end{array}$ \\
\hline CSphlb & 34 & $21(38 \%)$ \\
\hline O/Aphlb & 50 & $43(46 \%)$ \\
\hline
\end{tabular}

\section{Legends of Figures}

Figure 1: STS-PCR amplicons with ABC302.3 primers. The arrow indicates the Phlspecific ABC920 fragment, which is absent in the phlb mutant and the derived O/Aph1b plants 103-6, -8, -19, -27, -36, -39, -50, -61.

Figure 2: Meiotic metaphase I pairing in pollen mother cells of the CSph1b (a) and A/Ophlb (b-e) stock; multivalents are marked by arrowheads: a) one hexavalent, b) one trivalent plus one quadrivalent, c) one quadrivalent, d) one trivalent, e) one quadrivalent. 


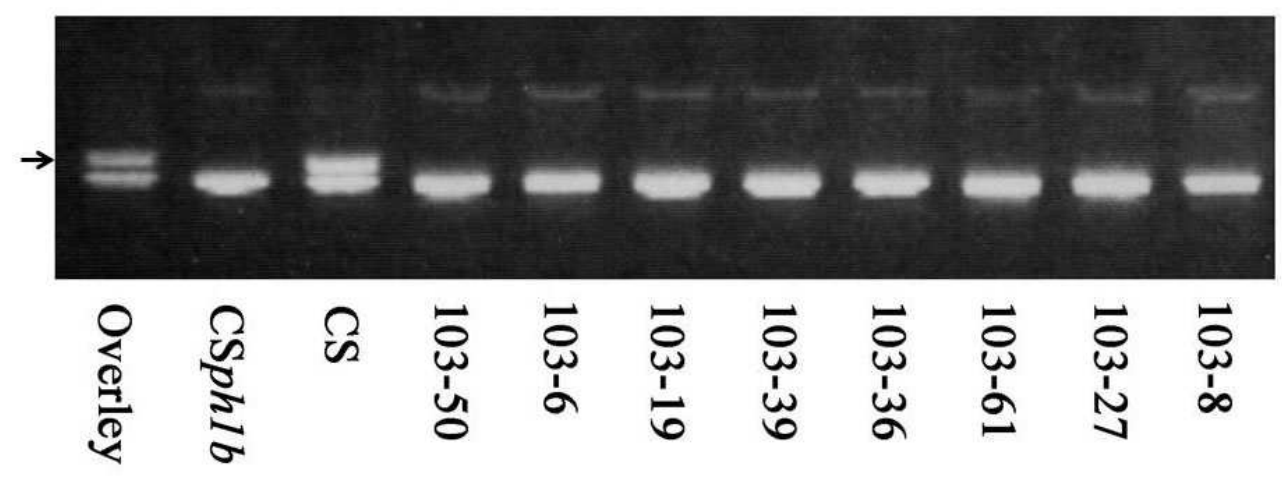

$246 \times 94 \mathrm{~mm}(96 \times 96 \mathrm{DPI})$ 

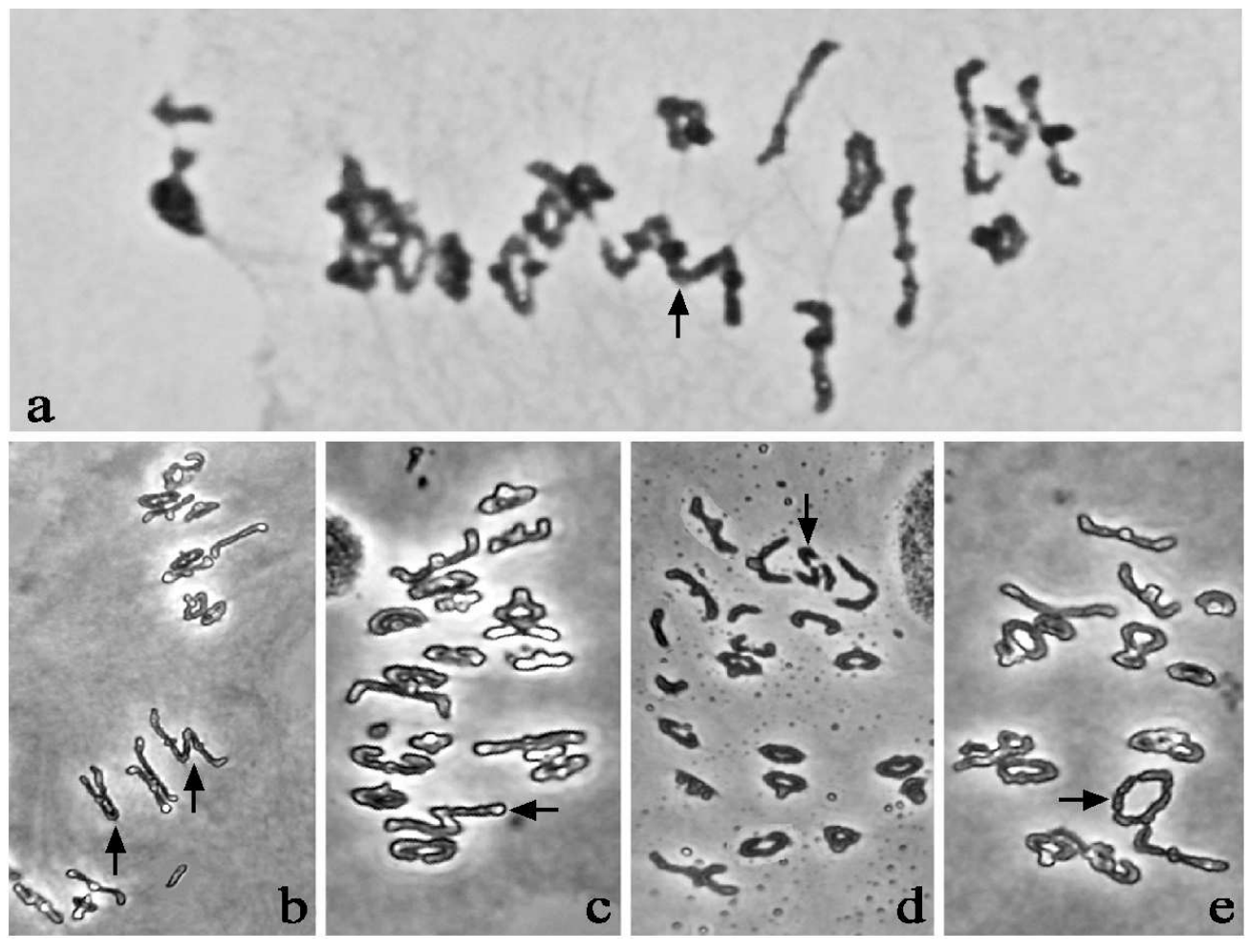

$104 \times 78 \mathrm{~mm}(300 \times 300$ DPI $)$ 